\title{
Effect of Tool Geometry and Process Parameters on Strength of Various Friction Stir Spot Welded Lap Joints
}

\author{
Manash J Borah ${ }^{1,2}$, Niharendu Saha ${ }^{2}$ \\ ${ }^{1}$ Programme of Mechanical Engineering, \\ Assam downtown University, Guwahati-26, India \\ manashjborah@adtu.in; nsaha.aec@gmail.com \\ ${ }^{2}$ Department of Mechanical Engineering, \\ Assam Engineering College, Guwahati-13, India
}

\begin{abstract}
Friction stir welding (FSW) is widely used in aerospace and automotive industries but this process can also be use to join various metals, which are for daily use. As aluminium alloys are used to manufacture most of the kitchen utensils but rivets are most commonly used to join them. For such type of joints, friction stir spot welding (FSSW) can be a good replacement or alternative to rivets. In the present study, FSSW lap joint is been carried out in a bench-drilling machine (spindle speed range of 750 RPM - 1341 RPM) to investigate the feasibility of such type of joints in small machine. The aim of this study is to investigate the effects of tool geometry and spindle speed on strength of friction stir welding at different joint. Two different types of tools i.e. circular probe tool and square probe tool are taken into consideration. The variation of welding strength with numbers of spot weld in the joint is also been discussed. The welding process is carried out for two types of joints, i.e., single spot FSW and double spot FSW lap joints. The welding material chosen for the process is aluminium alloy. The temperature recorded at the thermomechanical effected zone signifies that the welding is faster by square probe tool, which takes 20 to 25 seconds to get weld and reaches the highest temperature. The improvement of the process can make FSSW easier to use as a substitute of rivets.
\end{abstract}

Keywords: FSW, FSSW, Temperature Distribution, Strength Analysis, Double spot friction stir welding.

\section{Introduction}

Friction stir welding (FSW) that has been fancied by TWI [1] which has grown rapidly by its mechanical, natural and monetary advantages in various applications [2]. FSW is a nearly new strategy by that similar and dissimilar material can be joined within the solid state. It has reached a new level of maturity where high welding quality can be build up from favourable parameters [3, 4]. Tool geometry is very important factor for producing sound welds. Welding parameters, including tool rotation rate, traverse speed, spindle tilt angle, and target depth, are crucial to produce sound and defect-free weld [5-7]. FSW also has some unique advantages as compared to fusion welding. It is capable of fabricating steel joints with considerable toughness and strength [8]. The development of a semi-automated friction stir welding technique for joining $38 \mathrm{~mm}$ nominal outer diameter tubes of 6082-T6 aluminium alloy with $3.5 \mathrm{~mm}$ nominal wall thickness consists of retracting tool, which helps to avoid in leaving a hole in the sample at the welding line at the end of the welding process [9]. Tool structure, rotational speed, welding speed, dive profundity, Tool tilt edge and axial force square measure the fundamental parameters that affect FSW technique [10]. Tool configuration influences the flow and furthermore the power required for the technique, rotational speed influences the frictional heat, welding speed controls the created heat, dive profundity produces sound welds, tool tilt point influences the intensity of the weld and axial force produces more heating [11,12]. The microstructure developments of friction stir welded Al joints were characterized by Thread gill [13]. Anyway, this characterization cannot be summed up for all materials because of there is a refinement in conduct between $\mathrm{Al}$ alloys and option materials [14]. The Al friction stir welded joint is part into four zones: unaffected zone, heat influenced zone (HAZ), thermo naturally influenced zone (TMAZ) and dynamically recrystallized zone (DXZ). El_Sayed et al [15] had created limited part model to foresee the peak temperature produced all through FSW technique. They furthermore considered the after effect of FSW parameters of the peak temperature and furthermore the mechanical properties of AA5083-O friction stir welded. Jew et al. [16] had examined the after effect of geometrical parameters on AA5083-H111 friction stir welded T-Joints. Rao et al. [17] had incontestable the impact of tool pin profile on the microstructural properties and furthermore the corrosion conduct of AA2019 friction stir weld nuggets. A new refill friction spot welding process known as threaded Hole Friction Spot Welding (THFSW) is use to join AA5052 aluminium to short-carbon-fibber-reinforced polypropylene (PP-SCF) composite sheets where maximum shear-tensile strength of the joints reached to $80 \%$ of the composite base strength [18]. This process has eliminated the welding defect with a surface indentation of $0.3 \mathrm{~m}$ with 
Micro hardness at stir zone (SZ) was higher than that of the base material (BM)[19]. In this manner, the main idea of this investigation work is to audit the impact of the affixing velocities and dynamic the device stick profiles on the rubbing mix welded Al composites joints. Borah et al. [20] had filed a patent that illustrates the double spot friction stir welding and its uses at various sectors.

\section{Materials and Method}

\subsection{Material selection}

Aluminium and its alloys are low melting point metals and due to which, the fusion welding of aluminium and its alloys are quite difficult. Therefore, solid state welding is one of the possible welding method that is used for welding of such low melting point metal. Due to its multifaceted properties, Al alloys are mostly used for making kitchen utensils where mostly rivets are applied as fasteners. Therefore, friction stir spot welding can be a good replacement or alternative to rivet joint. The base material employed for the investigation was $3 \mathrm{~mm}$ thickness aluminium alloy AA6063, which has a melting point of about $650^{\circ} \mathrm{C}$. AA 6063 is an aluminium alloy, with magnesium and silicon as the alloying elements. It has a density of $2.68 \mathrm{~g} / \mathrm{cm} 3(0.0975 \mathrm{lb} / \mathrm{cubic}$ inch $)$ and it is widely used for architectural fabrication of windows and doorframes, pipe and tubing, aluminium furniture etc.

\subsection{Development of FSSW process}

The friction stir spot welding is been carried out in a bench-drilling machine of CROMPTON \& GRAVES with a spindle speed range of 750 RPM - 1341 RPM as shown in fig 1. The image in Fig 1 shows the rotational drive and the clamping system with the welding specimen mounted on the bed of the machine. The FSSW was accomplished for three parameters, viz. spindle speed, type of probe shape and number of spots of weld. Thus by full factorial method eight samples were welded by varying three different process parameters.

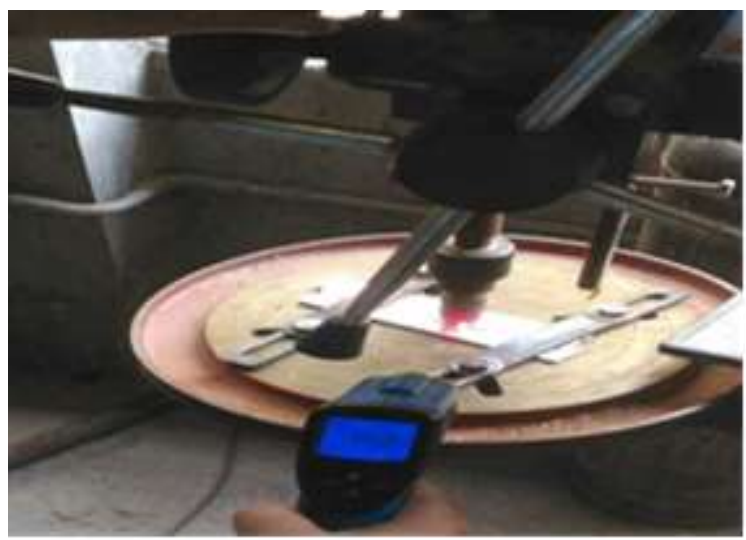

Fig. 1: Bench drilling machine showing the rotational drive and the clamping system mounted on the bed

It has to be ensured that the base material is properly clamped and tightened to prevent any displacement or movement caused during the welding process. The tool is fitted to the collet and is attached to the spindle of the drilling machine. The probe of the tool was just brought in contact manually with the base plates to be joined. Then the spindle is allowed to rotate at a specific speed. The temperature is measured by using a temperature laser gun at the heat affected zone as temperature measurement at the nugget zone is very complicated. At every five seconds the temperature is recorded.

\subsection{Tool material}

An integral step in the present work is to investigate the effect of tool on the FSSW joints. The tools were made of mild steel and the dimensions of the tool were taken so that the smallest collate fits the spindle of the drilling machine. Two different tools i.e. circular probe tool and square probe tool were used to weld the alloys at different spindle speed. Fig. 2 shows the top and the front view of the welding tool where the diameter of the shank, length of the tool and shoulder diameter are $12 \mathrm{~mm}, 44 \mathrm{~mm}$ and $12 \mathrm{~mm}$ respectively. 


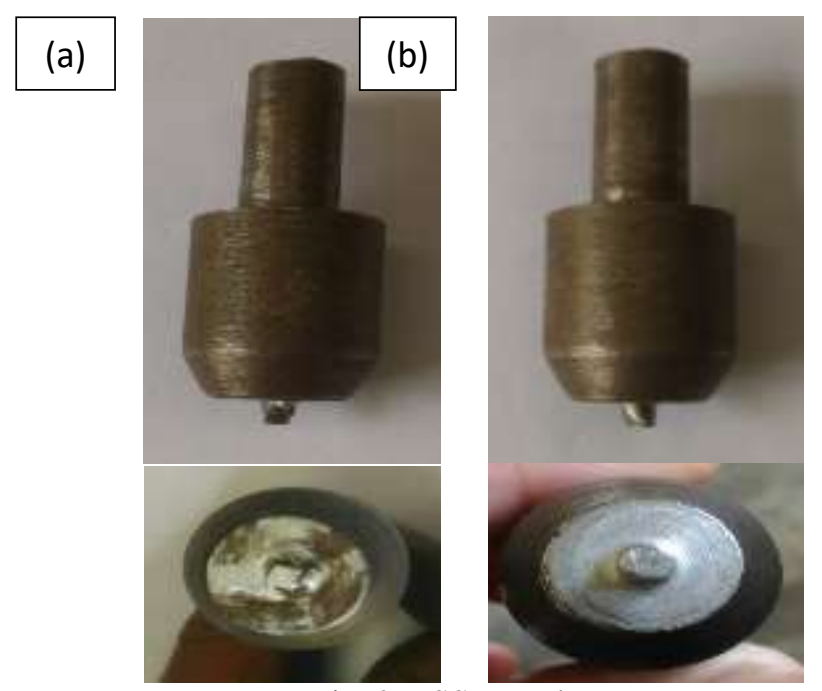

Fig. 2: FSSW tool.

a) Square probe Tool b) Circular probe tool

\subsection{Types of welded joint}

Types of weld joint is one of the major welding parameters for the analysis of the welding sample. Welding's were performed for two types of lap joint i.e. single spot friction stir lap joint and double spot friction stir lap joint. Fig. 3 shows two welding samples of single spot friction welding and double spot friction welding joints where the effect of tool geometry and spindle speed on the strength of the FSSW joints were investigated.

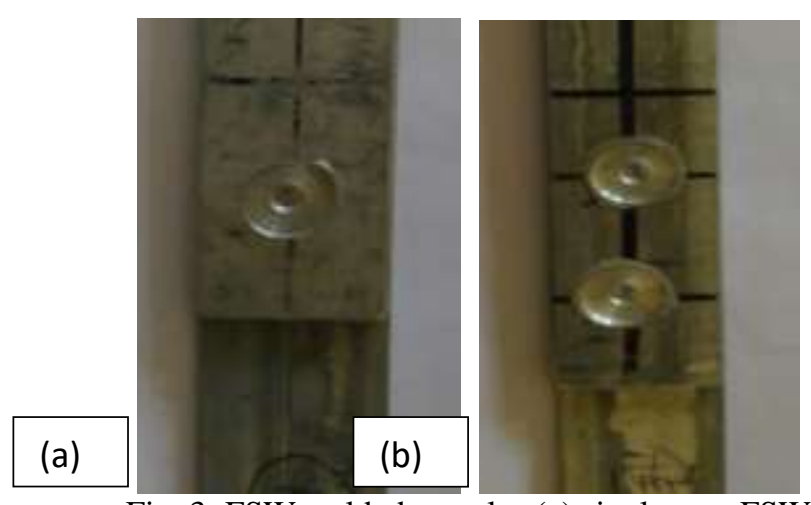

Fig. 3: FSW welded samples (a) single spot FSW

b) Double spot FSW.

\section{Results and Discussion}

The temperature at the heat affected zone (HAZ) and tensile strength of the spot welded samples were measured It is further analysed for the improvement of the FSSW process parameters in the bench drilling machine. The acquired data was studied for the comparison of temperature with different parameters. Thus, this information will come in handy for the advancement of the welding process by using the above-mentioned parameters.

\subsection{Temperature analysis}

A) Temperature Vs Speed

Fig 4 shows the relation between temperature and time of the FSSW joints by square probe tool at different spindle speed. The solid line in the graph represents the Temperature - Time variation for speed of 1349 RPM and semi-solid line is for 975 RPM. From the graph, the temperature at the HAZ for 1349 RPM gradually increased to $468 \mathrm{~K}$ at 25 seconds from the initial time and at a spindle speed of $975 \mathrm{RPM}$, the maximum temperature recorded was $451.5 \mathrm{~K}$, which has reached at 85 seconds from the initial time. The maximum temperature attained for both the parameters are almost same but the only difference observed is the welding time. 


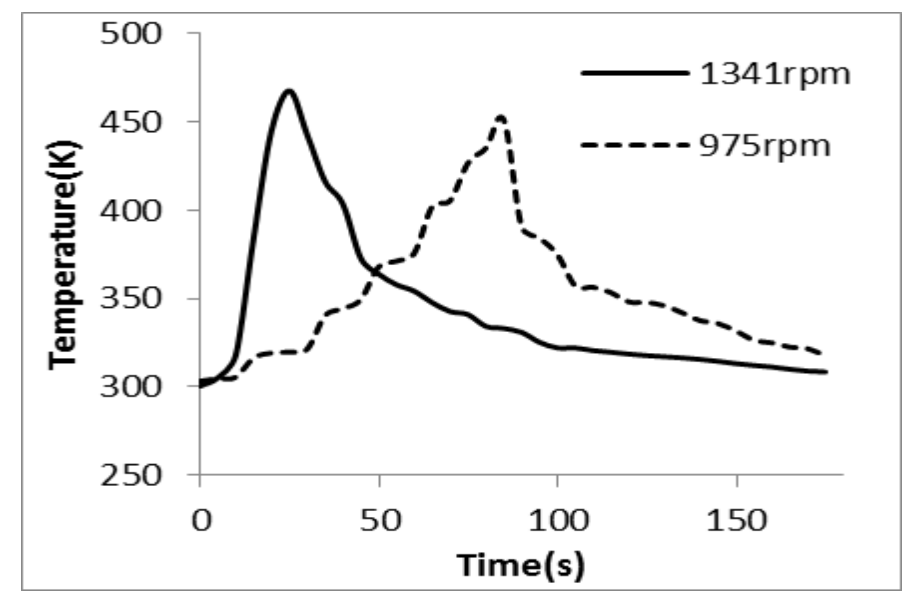

Fig. 4: Time v/s temperature graph at 975 and 1341 RPM using Square probe.

The heating rate as well as the cooling rate was faster for higher spindle speed. The time required for attaining the maximum temperature at $1341 \mathrm{RPM}$ is less as compared to temperature at $975 \mathrm{RPM}$, i.e. for higher spindle speed. The friction stir welding process was faster at higher spindle speed than lower spindle speed.

\section{B) Temperature Vs Probe Shape}

The temperature time variations were analysed for two different probe shape i.e. square probe and circular probe at constant spindle speed of 1341 RPM. Fig. 5 shows the effect of probe shape on temperature variation during welding. The solid line in the plot resemble the weld by circular probe tool and the dotted line if for welded joints by square probe tool. The temperature rises to $468 \mathrm{~K}$ at a time of 25 seconds from the initial time and while using a circular probe the maximum-recorded temperature is $458.6 \mathrm{~K}$ within a time span of 60 seconds from the initial time. From the data reported, it could be arrived at an opinion that square probe takes less time to weld as compared to circular probe due to high friction between the tool and the weld sample, which leads to better stirring effect of the welded sample.

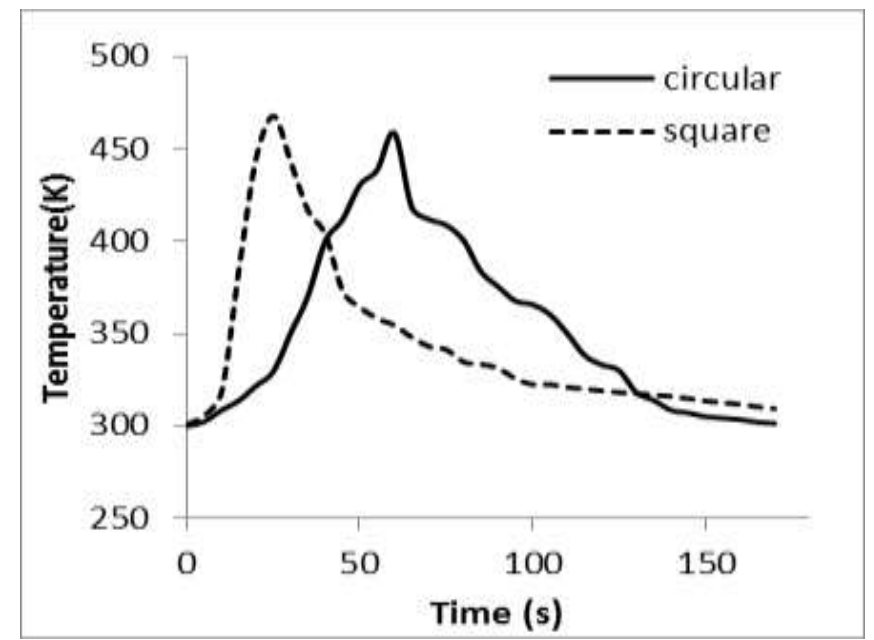

Fig. 5: Time v/s Temperature graph at 1341 RPM using circular and square probe.

\subsection{Strength measurement}

The tensile strength has been recorded for all the samples at different parameters. The tensile test has been evaluated at maximum load of $100 \mathrm{kN}$, which is electro-mechanical controlled Universal Testing Machine (INSTRON). The specimens were loaded at the strain rate of $2 \mathrm{~mm} / \mathrm{min}$ as per the specifications is attached to specimen, the gauge length is taken as $50 \mathrm{~mm}$, width as $4.5 \mathrm{~mm}$ and total length of $100 \mathrm{~mm}$ so that tensile specimen undergoes deformation. The specimen finally fails after necking and the load versus displacement is been recorded. The $0.2 \%$ offset yield strength; ultimate tensile strength and percentage of elongation is been evaluated. 


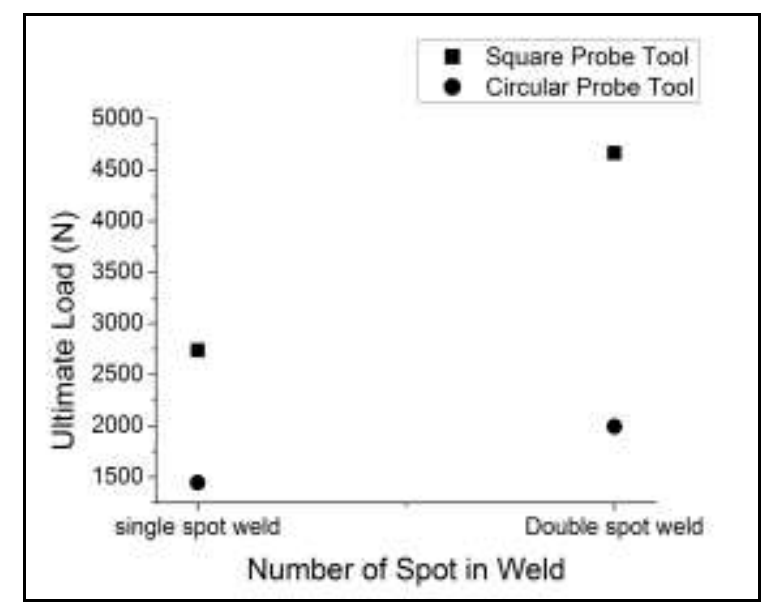

Fig. 6: Strength at 975 RPM using circular and square probe.

The plots in fig. 6 shows the ultimate loads measured for the welding parameters for 975 RPM by two different tools. In the fig 6 , the circular bullet in the graph resembles the circular probe tool and square bullet signifies the square probe tool. Here it is been observed that for same numbers spot in welding sample, the withstanding load by the welded joint was higher for the sample where square probe tool was used to weld. The maximum load that can hold by the welded joints recorded was $4666.901 \mathrm{~N}$. The withstanding capacity of the spot-welded joints increases as the number of spots in the weld increases. The strength of the welding joints can also be increased by increasing the numbers of spots in the welds and using square probe was efficient than using circular probe.

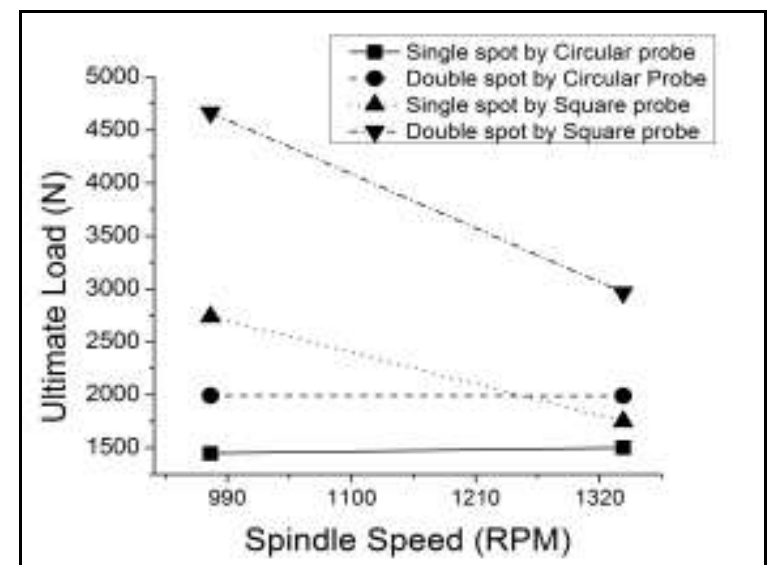

Fig. 7: Load v/s Spindle speed using circular and square probe.

Spindle speed is one of the important parameters, which decides the strength of the joints. The relation between the ultimate loads that can withstand by the welding joints at different spindle speed is plotted in Fig. 7. It has been noticed that by using circular probe tool, the strength of the welding sample at two different speeds is almost same. For square probe tool, the withstanding load was more at lower spindle speed of 975 RPM. The ultimate bearing load was 4666.6 $\mathrm{N}$, which was noted for double spot friction welding lap joint, which signify that the double spot welding by a square probe tool can bear maximum load of $4666.6 \mathrm{~N}$.

\subsection{Temperature and strength comparison}

From the temperature analysis, it is been observed that the welding was faster while using square probe tool, which take 20 to 25 seconds to get weld and reaches the highest temperature. Also from the strength plots, it is been observed that higher strength was achieved from the welds of square probe tool. However, at higher spindle speed of 1329 RPM the strength of the welding joint was less than that of lower spindle speed. As the maximum temperature recorded for all the parameters was almost same for all the joints. Therefore, it indicates that the effect of heat generation in the HAZ was considerably less. 


\section{Conclusion}

From the results, it is concluded that by using square probe and spindle speed of 945RPM highest strength of the welding joint was recorded with an efficiency of 35\%-40\%. The withstanding load capacity of the spot-welded joints increases as the number of spots in the weld increases. Therefore, the efficiency of the welding joints can be improved by increasing the numbers of spots in the welds. The efficiency also depends on the clamping of the workpiece and speed of the spindle speed which can be future studied to improve the welding efficiency. All the convincing results defines clearly about the feasibility of FSSW in a bench-drilling machine. The improvement of the process can also make FSSW easier to use as a substitute of rivets.

\section{Acknowledgments}

We would like to thank all the personals of mechanical Engineering workshop of Assam down Town University and Assam Engineering College, Jalukbari who were involved with this project and providing the facilities required. We would also like to extend our sincere gratitude to the Department of Mechanical Engineering, IIT Guwahati for allowing us to work in the laboratory of Strength of Material.

\section{References}

[1] T. M. Wayne, E. D. Nicholas, J. C. Needham, M. G. Murch, P. Temle-Smith, C. J. Dawes, European Patent. No. EP0615480, 1991.

[2] B. R. Singh, A Handbook of FSW, LAP LAMBERT Academic Pub. Saarbruken, pp. 151-163, 2012.

[3] S. Sattari, H. Bisadi, M. Sajed, "The Mechanical Properties and Temperature Distributions of Thin Friction Stir Welded Sheets of AA5083." International journal of mechanics and application, vol. 2, no. 4, pp.1-6, 2012.

[4] G. S. Vacchia, A. H. Plaineab, R. Silvaa, V.L. Sordia, U. F. H. Suhuddinb, N. G. Alcântaraa, S. E. Kuria,C. A. D. Rovere, "Effect of friction spot welding (FSpW) on the surface corrosion behavior of overlapping AA6181T4/Ti-6Al-4V joints," Material and design, vol. 131, pp. 127-134, 2017.

[5] A. H. H. Plaine, A. R. R. Gonzalez, U. F. H. F. H. Suhuddin, J. F. F. dos Santos, N. G. G. Alcântara, "The optimization of friction spot welding process parameters in AA6181-T4 and Ti6A14V dissimilar joints," Materials \& Design, vol. 83, pp. 36-41, 2015.

[6] Manash Jyoti Borah, Palash Saikia, "The experimental analyses on welding strength of friction stir welding of AA 6063 at different parameters," Discovery Journal, vol. 52, pp.1345-1351, 2016.

[7] Prasanna Kutum, Manash Jyoti Borah, "Experimental analysis on friction stir welding process parameters on temperature Distribution," Indian Journal of Engineering, vol. 13, pp. 394-400, 2016.

[8] Y. Ding, Z. Shen, A. P. Gerlich, "Refill friction stir spot welding of dissimilar aluminium alloy and AlSi coated steel," Journal of manufacturing processes, vol. 30, pp.353-360, 2017.

[9] D. G. Hattingha, L. G. vonWelligh, D. Bernard, L. Susmel, R. Tovo, M. N. James, "Semi-automatic friction stir welding of 38mm OD 6082-T6 aluminium tubes," Journals of materials processing technology, vol. 238, pp. 255-266, 2016.

[10] F. C. Liua, Y. Hovanskib, M. P. Milesb, C. D. Sorensena, T. W. Nelsona, "A review view of friction stir welding steels: Tool, material flow, microstructure and properties," Journal of material science and technolog, vol. 34, pp. 39-57, 2018.

[11] R. S. Mishra, Z. Y. Ma, "Friction stir welding and processing," Materials Science and Engineering, vol. 50, pp. $1-78,2005$.

[12] FSW-Technical-Handbook. ESAB, Welding Automation, SE-695 81 LAXÅ; Sweden.

[13] P. L. Threadgill, TWI Bull, vol. 28, pp. 30-33, 1997.

[14] P. L. Threadgill, A. J. Leonard, H. R. Shercliff, P. J. Withers, "Friction Stir Welding Of Aluminum Alloys," International Materials Reviews, vol. 54, no. 2, pp. 49-93, 2009.

[15] M. M. El Sayed, A. Y. Shash, T. S. Mahmoud, M. Abd Rabou, "Thermal Distribution In Friction Stir Welding Of AA5083, Numerical Simulation, Experimental Verification and The Post-weld Mechanical Properties Measurements Of The Welded Joint," in Proceedings of the 10th international conference ACE-X; Split-Croatia, 2016

[16] J. S. Jesus, M. Gruppelaar, J. M. Costa, A. Loureiro, J. A. M. Ferreira, "Effect of Geometrical Parameters on Friction Stir Welding of AA5083-H111. XV," in Proceedings of Portuguese Conference on Fracture PCF, 2016.

[17] RAO Ch V, REDDY G.M, RAO K.S, "Influence of Tool Pin Profile on Microstructure and Corrosion Behavior of AA2219 Ale-Cu Alloy Friction Stir Weld Nuggets,” Defense Technology, vol. 11, pp. 197-208, 2015. 
[18] Hossein Karami Pabandi, Mojtaba Movahedi, Amir Hossein Kokabi, "A new refill friction spot welding process for aluminium polymer composite hybrid structures," Composite structures, vol. 174, pp. 59-69, 2017.

[19] Zhiwu Xua, Zhengwei Lia, Shude Jib, Liguo Zhang, "Refill friction stir spot welding of 5083-O aluminium alloy," Journal of material science and technology, vol. 34, pp. 878-885, 2017

[20] Manash J Borah, Niharendu Saha, Intellectual property India. Application no TEMP/E-1/49294/2018-KOL, 2018. 